\title{
Mixing in a density-driven current flowing down a slope in a rotating fluid
}

\author{
CLAUDIA CENEDESE ${ }^{1}$ AND CLAUDIA ADDUCE \\ ${ }^{1}$ Woods Hole Oceanographic Institution, Woods Hole, MA 02543, USA \\ ${ }^{2}$ Universita' RomaTre, Via Vito Volterra, 62, 00146 Roma, Italy
}

(Received 24 May 2006 and in revised form 25 February 2008)

We discuss laboratory experiments investigating mixing in a density-driven current flowing down a sloping bottom, in a rotating homogenous fluid. A systematic study spanning a wide range of Froude, $0.8<F r<10$, and Reynolds, $10<R e<1400$, numbers was conducted by varying three parameters: the bottom slope; the flow rate; and the density of the dense fluid. Different flow regimes were observed, i.e. waves (non-breaking and breaking) and turbulent regimes, while changing the above parameters. Mixing in the density-driven current has been quantified within the observed regimes, and at different locations on the slope. The dependence of mixing on the relevant non-dimensional numbers, i.e. slope, $F r$ and $R e$, is discussed. The entrainment parameter, $E$, was found to be dependent not only on $F r$, as assumed in previous studies, but also on $R e$. In particular, mixing increased with increasing $\mathrm{Fr}$ and $R e$. For low $\mathrm{Fr}$ and $R e$, the magnitude of the mixing was comparable to mixing in the ocean. For large $F r$ and $R e$, mixing was comparable to that observed in previous laboratory experiments that exhibited the classic turbulent entrainment behaviour.

\section{Introduction}

Density-driven currents are generated in the ocean either in marginal seas, where evaporation induces an increase in density, or at high latitudes, where either strong atmospheric cooling and/or ice formation with consequent brine rejection, contribute to increasing the water density. Oceanic observations revealed different examples of dense currents such as the Mediterranean outflow (Price et al. 1993; Baringer \& Price 1997); the outflows through the Denmark Strait (Dickson \& Brown 1994; Girton \& Sanford 2003) and the Faroe Bank Channel (Saunders 1990; Mauritzen et al. 2005); and dense currents at various locations along the Arctic (Aagaard, Coachman \& Carmack 1981) and Antarctic (Foster \& Carmack 1976) continental shelves. Dense currents may flow over a sill and/or through a constriction in width to then descend on the continental slope for long distances, until they either encounter the ocean bottom or interleave at their level of neutral buoyancy. At the sill/constriction or during descent, dense currents have been observed to mix with the ambient fluid above; the amount of entrained fluid dictates the final properties of the dense currents (such as density for example) and hence, the final location of the resultant water mass, i.e. at the bottom of the ocean or at a neutrally buoyant depth. The final properties of dense current water masses are of global importance since they become part of the thermohaline circulation. For example, the North Atlantic Deep Water (NADW) is one of the most important sources of deep water in the oceans. It originates from 
the Greenland Sea and its water properties depend mainly on the entrainment in the dense currents through the Denmark Strait and Faroe Bank Channel.

The dynamics of a dense current flowing down a slope have been modelled in the past, both theoretically and experimentally, starting with Ellison \& Turner (1959) and Britter \& Linden (1980). A simplified 'streamtube' model was proposed by Smith (1975) and Killworth (1977), and revisited by Price \& Baringer (1994). However, this model and coarse resolution global climate models, do not resolve the overflow region and the associated dynamics, and rely on bottom boundary layer and entrainment parameterizations. To date, models that do not resolve entrainment processes use a supercritical Froude number $\left(F r=U / \sqrt{g^{\prime} H \cos \theta} \geqslant 1\right.$, where $U, g^{\prime}$ and $H$ are the current velocity, reduced gravity and vertical scale, respectively, and $\theta$ is the slope angle) parameterization often based on the results of Ellison \& Turner (1959). The entrainment velocity $W e=E U$ is considered to be proportional to the local mean velocity of the flow, $U$, and the entrainment function $E$ can be represented, based on Ellison \& Turner's (1959) experiments, and subsequent analysis (Turner 1986), as a function of $\mathrm{Fr}$ in the form

$$
E= \begin{cases}\frac{0.08 F r^{2}-0.1}{F r^{2}+5} & \text { for } F r^{2} \geqslant 1.25 \\ 0 & \text { for } F r^{2}<1.25\end{cases}
$$

Many numerical modelling studies have investigated overflow and mixing dynamics (Jiang \& Garwood 1996; Jungclaus, Hauser \& Käse 2001; Käse, Girton \& Sanford 2003; Ezer 2005; Özgökmen, Fischer \& Johns 2006; Legg, Hallberg \& Girton 2006; $\mathrm{Xu}$ et al. 2006; Jackson, Hallberg \& Legg 2008), and very high resolution regional models (Riemenschneider \& Legg 2007) focus on a better understanding of the overflow dynamics to help formulate correct parameterizations in large-scale models.

An area of active research in the past five years has been focused on finding new ways to parameterize mixing in dense currents. Rotating laboratory experiments (Cenedese et al. 2004), have identified different flow regimes of dense currents on a slope, and the results have been confirmed in a recent numerical study by Ezer (2006). Furthermore, Wells \& Wettlaufer (2005) reproduced the non-rotating experimental results of Ellison \& Turner (1959) and the mixing generated in a rotating dense current was further analysed by Wells (2007). Non-rotating experiments investigating mixing in a dense current flowing down-slope in a stratified fluid were also conducted by Baines $(2001,2002,2005)$ for different slope angles.

The results of Cenedese et al. (2004, hereinafter referred to as CWAO) suggest that entrainment in dense currents can occur for subcritical Froude numbers, $F r<1$, a fundamental difference from the Ellison \& Turner (1959) parameterization (1.1). Wåhlin \& Cenedese (2006) and Hughes \& Griffiths (2006) pointed out that subcritical mixing could be of fundamental importance in determining the final properties of the dense current, especially if its path length to the bottom of the ocean, or to its level of neutral buoyancy, is long. Weak subcritical entrainment, if it occurs over long distances, could be as effective as strong supercritical entrainment occurring near a sill or a constriction. The non-rotating experiments performed by Wells \& Wettlaufer (2005) showed that for low slope angles, the total entrainment occurring over a fixed vertical distance is constant and independent of the slope angle. This result can be explained by the increased path length that the dense current has to flow, for small slope angles, to fall the same vertical distance, in agreement with Wåhlin \& Cenedese (2006) and Hughes \& Griffiths (2006). 
This paper is an extension of CWAO, but here the main focus is on quantifying the mixing that occurs between the dense current and the ambient fluid for a wide range of Froude $(0.8<F r<10)$ and Reynolds $(10<R e<1400$, where $R e=U H / v$, and $v$ is the kinematic viscosity) numbers. The aim of this study is to illustrate the mixing dependence on both the Froude and Reynolds numbers. The paper is organized as follows. The experimental apparatus is described in $\$ 2$. A qualitative description of a typical experiment is presented in $\S 3$, and the relevant non-dimensional numbers are discussed in $\S 4$. In $\S 5$, we investigate the dependence of mixing on slope angle, while the dependence of mixing on the Froude and Reynolds numbers is illustrated in $\S 6$. Mixing measurements at four locations on the slope are discussed in §7. Finally, we compare our results to ocean measurements and previous laboratory experiments in $\S 8$. The conclusions of this work are discussed in $\S 9$.

\section{Experimental apparatus}

The experiments were conducted in a glass tank of depth $90 \mathrm{~cm}$ and length and width $58 \mathrm{~cm}$. The tank was mounted on a $1 \mathrm{~m}$ diameter rotating turntable with a vertical axis of rotation (figure 1). We used a square tank to avoid optical distortion from side views associated with a circular tank. The bottom of the tank had a slope $s=\tan \theta$, where $\theta$ is the angle between the slope and the horizontal. The tank was filled with freshwater of density $\rho_{1}$, which was initially in solid-body rotation. A reservoir of salted and dyed water of density $\rho_{2}>\rho_{1}$ was placed on the rotating table and connected to a source on the sloping bottom, via a pump and a plastic tube. The source was positioned on the right-hand side (looking upslope) of the shallowest part of the tank and consisted of a plastic rectangular box $\left(6 \times 6.7 \mathrm{~cm}^{2}\right)$ with the wall looking down-slope, $0.5 \mathrm{~cm}$ in height, removed. The plastic tube from the pump was connected to an opening made on the top of the source, and the dense water filled the source thickness and then exited on the down-slope side (see figure 1a). A 5 $\mathrm{cm}$ high wall was attached, orthogonal to the end and sides of the slope (dotted line in figure 1a). The dense water collected, without any further mixing, in the pocket created by this wall at the end of the slope after descending the slope (see figure $1 a$ ). Samples were withdrawn during each experiment through small-diameter tubes $(d=$ $0.15 \mathrm{~cm})$ placed at the bottom of the pocket in three different sampling positions, denoted 0,1 and 2, with a spacing of $15 \mathrm{~cm}$ (figure $1 b$ ). The mean density of the three samples was used to determine the density of the gravity current at the end of the slope. The values of density measured at these three locations were similar, as indicated by the small $90 \%$ confidence interval in figure 4 . As discussed in $\S 3$ and in CWAO, we hypothesize that the mixing between the overlying light fluid and the dense current is caused by highly nonlinear waves and turbulence, and that the mixing encompasses the entire fluid within the density current. Therefore, the fluid in the pocket at the end of the slope is assumed to be of uniform density; that is, the lower dense layer is well mixed. In order to measure densities at different locations along the current trajectory on the slope, two sets of four holes were drilled on the slope $(A-D$ and $A^{\prime}-D^{\prime}$ in figure $1 b$ ), and also connected to $0.15 \mathrm{~cm}$ diameter sample tubes. Samples were taken continuously at each location during an experiment. Different experiments presented different current trajectories (figures 2 and 3). However, after an accurate observation of the current trajectories for a selected number of experiments, it was clear that the two sets of sampling points were sufficient to cover the trajectories of the selected experiments. For a given experiment, only the set of sampling points closer to the centreline of the current was used. As mentioned above, the density 

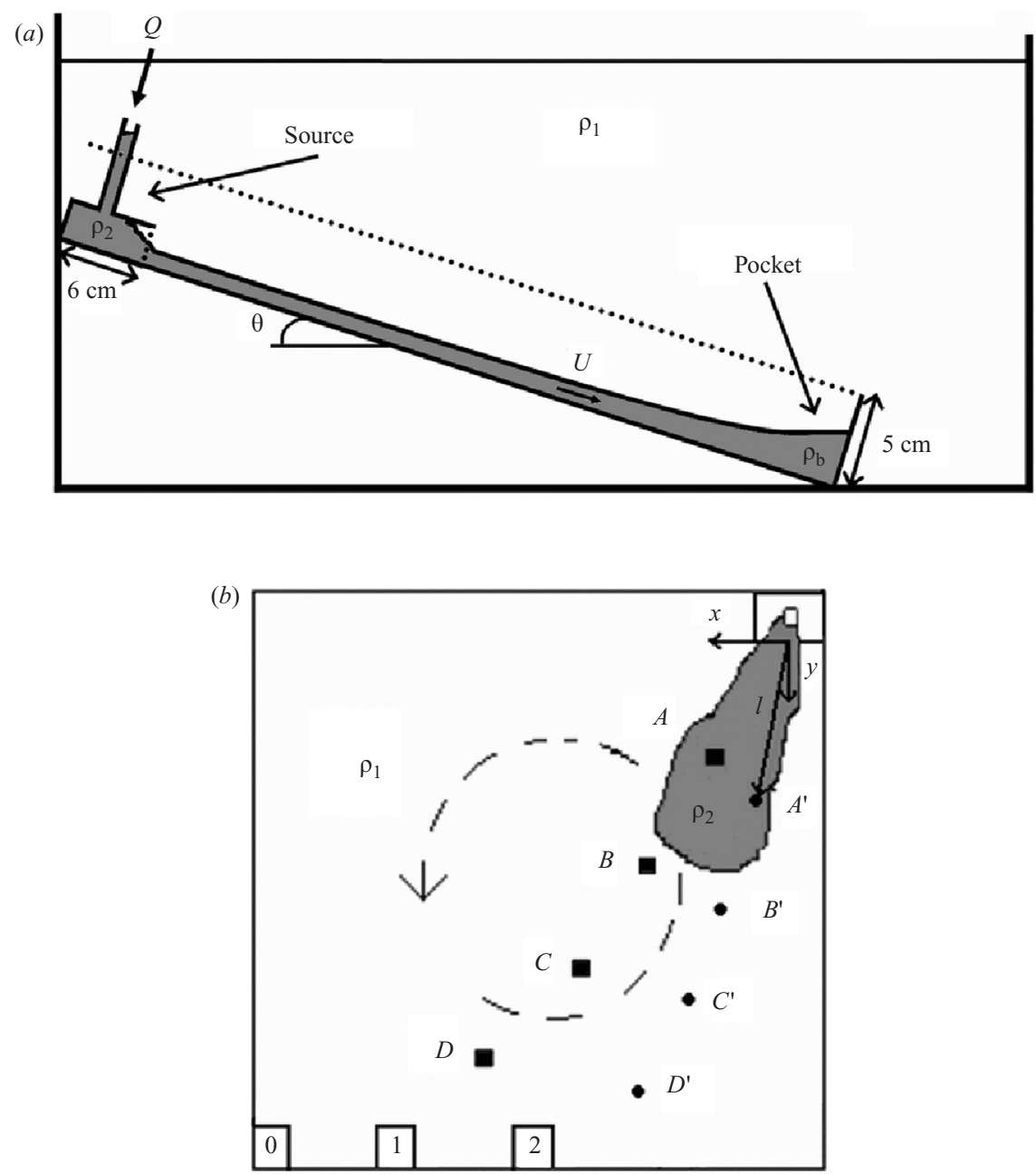

FIGURE 1. Sketch of the experimental apparatus: (a) side view of the rotating tank with the source positioned at the top of the slope, and the pocket positioned at the end of the slope; (b) top view of the slope together with the $(x, y)$ system of reference. The dashed arrow indicates the counterclockwise direction of rotation of the table. Not to scale.

measurements on the slope were not performed for all the runs, only for a selected number of experiments.

A total of 57 experiments were conducted. After the ambient fluid was spun up, the experiment started by turning on the pump. A dense current was generated and, at the end of each experiment, the water in the tank was mixed and a new ambient density was measured for the next experiment. A video camera was mounted above the tank and fixed to the turntable so that measurements were obtained in the rotating frame. The dense current was made visible by dyeing the fluid with food colouring, and was observed both from the top and the side. The flow at the free surface was observed by adding buoyant paper pellets.

The depth of the freshwater on the shallowest side of the tank, $h_{0}$, was kept constant at $10 \mathrm{~cm}$ for every slope inclination. The value of the Coriolis parameter was $f=1$ $\mathrm{s}^{-1}$ in all experiments except for two in which $f=1.75 \mathrm{~s}^{-1}$. The bottom slope $s=$ 
$\tan \theta$ varied between 0.45 and 8.6, and the dense fluid was pumped in at a flow rate $Q=2.5$ or $8.3 \mathrm{~cm}^{3} \mathrm{~s}^{-1}$. The buoyancy forces are described by the reduced gravity defined as

$$
g^{\prime}(l)=g \frac{\rho_{2}^{*}(l)-\rho_{1}}{\rho_{1}},
$$

where $g$ is the acceleration due to gravity, $\rho_{2}^{*}(l)$ is the density of the gravity current measured at a distance $l$ from the source (figure $1 b$ ). The reduced gravity at the beginning of the experiment

$$
g_{0}^{\prime}=g \frac{\rho_{2}-\rho_{1}}{\rho_{1}},
$$

took values between 0.7 and $99.8 \mathrm{~cm} \mathrm{~s}^{-2}$. The densities were determined with a DMA58 Anton Paar densitometer with an accuracy of $10^{-5} \mathrm{~g} \mathrm{~cm}^{-3}$.

\subsection{Bulk parameter definitions}

As described in detail in the next section, the dense current evolved while descending the slope. Hence, the parameters characterizing the current properties, such as the current thickness, density and velocity, changed as the current moved down the slope. To characterize each experiment with a single value of these parameters, we introduce their 'bulk' or average values.

The median of the reduced gravity, $g_{m}^{\prime}$, has been calculated for all experiments using the available measured densities of the current on the slope (i.e. at the source, at the end of the slope, and, for a selected number of experiments, the measured density at four locations on the slope). The median is a useful quantity in cases where the distribution has very large extreme values which would otherwise skew the data and it was found to be a better indicator of the bulk reduced gravity than the mean, especially in those experiments where a large entrainment occurred immediately after the source. A bulk value of the current thickness has been defined as $H_{m}=\left(Q+Q_{e}\right) \Delta t / A$, where $Q_{e}$ is the entrained fluid flow rate and $\Delta t$ is the time interval it takes for the dense current to reach the end of the slope and cover an area $A$ on the slope. Using the mass conservation equation, the entrained fluid flow rate is given by

$$
Q_{e}=Q \frac{\rho_{2}-\rho_{b}}{\rho_{b}-\rho_{1}}=Q\left(\frac{1}{r_{b}}-1\right),
$$

where $\rho_{b}$ and $r_{b}$ are the density of the current and the mixing ratio, respectively, both measured at the end of the slope. The mixing ratio, $r(l)$, is defined as the ratio between the reduced gravity measured at a distance $l$ from the source, $g^{\prime}(l)$, and at the beginning of the experiment, $g_{0}^{\prime}$,

$$
r(l)=\frac{\rho_{2}^{*}(l)-\rho_{1}}{\rho_{2}-\rho_{1}}=\frac{g^{\prime}(l)}{g_{0}^{\prime}} .
$$

Hence, $r_{b}=g_{b}^{\prime} / g_{0}^{\prime}$, where $g_{b}^{\prime}$ is the reduced gravity measured at the end of the slope. Measuring the area $A$ on the slope covered by the dense current using the video images, a mean thickness of the dense current, $H_{m}$, can be calculated by

$$
H_{m}=\frac{Q \Delta t}{r_{b} A} .
$$

In order to evaluate the influence of the dynamically relevant non-dimensional numbers, the down-slope velocity of the dense current had to be measured. A bulk 
(a)
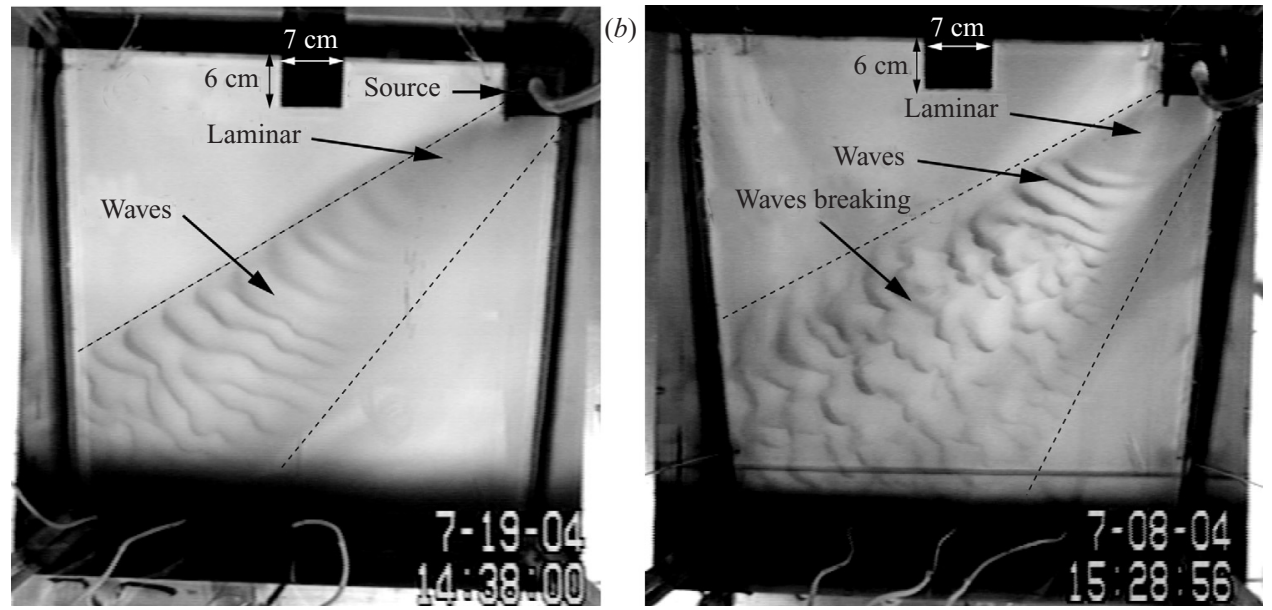

FIGURE 2. Top view of the density current: ( $a$ ) non-breaking waves regime for $Q=2.5 \mathrm{~cm}^{3}$ $\mathrm{s}^{-1}, f=1 \mathrm{~s}^{-1}, g_{0}^{\prime}=4 \mathrm{~cm} \mathrm{~s}^{-2}$, and $s=0.45$; and $(b)$ breaking-waves regime for $Q=2.5 \mathrm{~cm}^{3}$ $\mathrm{s}^{-1}, f=1 \mathrm{~s}^{-1}, g_{0}^{\prime}=4 \mathrm{~cm} \mathrm{~s}^{-2}$, and $s=0.7$. The calculated average current thickness is $(a)$ $H_{m}=0.18 \pm 0.003 \mathrm{~cm}$ and $(b) H_{m}=0.18 \pm 0.009$. The dotted lines indicate the approximate edges of the current.

value for the current velocity was obtained by measuring the time and distance covered by the 'head' of the dense current from the source to the end of the slope. Hence, using video images, an average velocity, $U_{m}$, was calculated. We expect the head velocity to be lower than the velocity of the dense current behind it, as discussed in §3. Measurements of the current velocity as in CWAO were not possible for the present study. CWAO velocity measurements were performed using a cross-correlation technique, based on the identification of the wave crests on the density current. In the present experiments, however, the wave crests broke (as discussed in $\$ 3$ ), and it was not possible to delineate and track the wave crests over the whole current as it descended the slope.

\section{Qualitative description of a typical experiment}

During each experiment, the dense fluid was released continuously from the source. This fluid first moved down-slope, then it was deflected to the right (looking downslope) by the effect of rotation. The resultant density current presented the classic 'head' where some mixing occurred (Simpson 1997), followed by a thinner fluid layer. As described in CWAO, different flow regimes were observed: laminar; waves (non-breaking and breaking); turbulent; and eddies. The range of parameters in the present experiments was much broader than in CWAO, and a careful investigation of the turbulent and waves-breaking regimes, missing in CWAO, was conducted. A brief qualitative description of the four regimes will follow.

(i) Laminar regime. The dense fluid behind the head had an approximately constant thickness and presented a sharp interface with the ambient fluid, indicating that very little mixing, if any, occurred between the two fluids. No circulation was observed on the free surface.

(ii) Waves regime. Wave crests were observed to travel in the same direction as, but faster than, the density current head. As the waves descended down-slope, they grew in amplitude, and two different regimes were observed. In the non-breaking waves regime (figure $2 a$ ), the waves did not break and a small amount of mixing occurred 
(a)

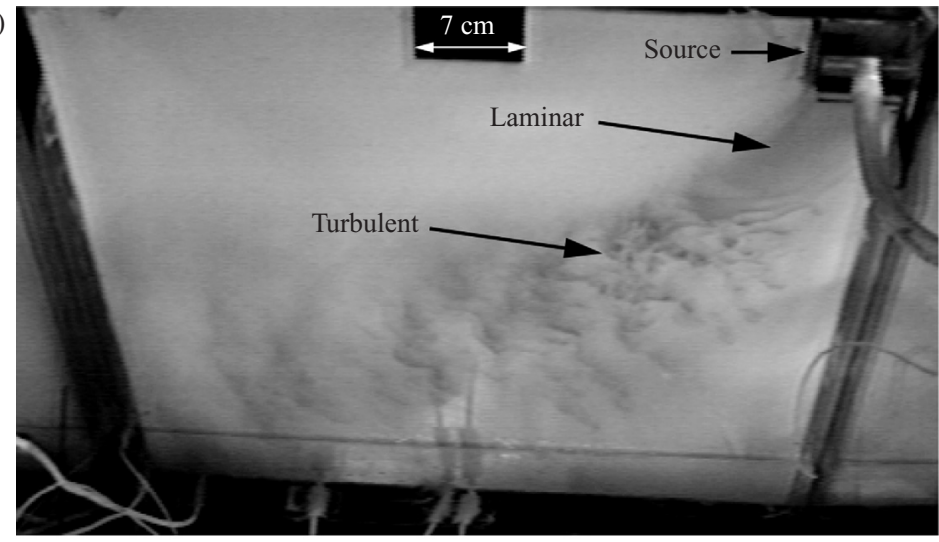

(b)

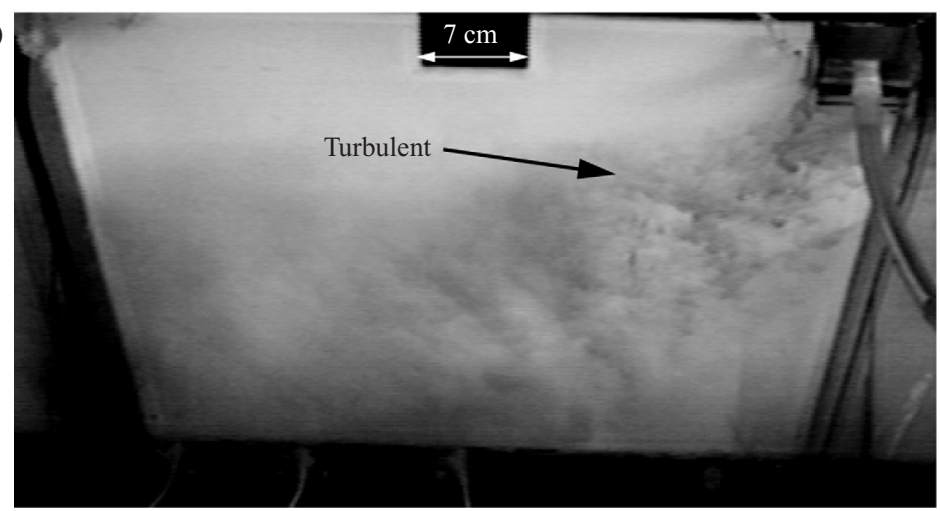

FIGURE 3. Top view of the density current turbulent regime: $(a)$ with a laminar region near the source for $Q=2.5 \mathrm{~cm}^{3} \mathrm{~s}^{-1}, f=1 \mathrm{~s}^{-1}, g_{0}^{\prime}=4 \mathrm{~cm} \mathrm{~s}^{-2}$, and $s=2$; and $(b)$ with a turbulent region immediately after the source for $Q=8.3 \mathrm{~cm}^{3} \mathrm{~s}^{-1}, f=1 \mathrm{~s}^{-1}, g_{0}^{\prime}=9.8 \mathrm{~cm}$ $\mathrm{s}^{-2}$, and $s=2.1$. The calculated average current thickness is $(a) H_{m}=0.53 \pm 0.041 \mathrm{~cm}$ and $(b)$ $H_{m}=1.28 \pm 0.110 \mathrm{~cm}$.

at the interface between the ambient and dense fluids, as shown later by the triangles in figures 6 and 7. For some parameter values, the amplitude of the waves became so large that they broke in a three-dimensional fashion (figure $2 b$ ). In the breaking-waves regime, considerable mixing between the dense and ambient fluids occurred, as shown later by the stars in figures 6 and 7. No circulation was observed on the free surface.

(iii) Turbulent regime. Two kinds of turbulent density currents were observed. The first one had a laminar region close to the source (figure $3 a$ ), followed downstream by a turbulent region. In other cases, a turbulent region developed immediately after the source (figure $3 b$ ). The turbulent regime presented the largest mixing between the dense and ambient fluids, as shown later by the diamonds in figures 6 and 7. No circulation was observed on the free surface.

(iv) Eddies regime. In some experiments, the buoyant paper pellets on the free surface revealed the presence of cyclonic eddies in the freshwater above the dense fluid (Whitehead et al. 1990; Lane-Serff \& Baines 1998; Spall \& Price 1998; Etling et al. 2000; and CWAO). A possible mechanism of eddy generation is described in CWAO. The eddies were observed to move to the right as they travelled, until they reached the wall of the tank. They contributed to a small amount of mixing between the dense and ambient fluids. 
In some cases, two or three of the described regimes (i.e. laminar, waves and turbulent) were observed simultaneously in the same experiment, occurring successively down the slope.

\section{Non-dimensional parameters}

The dimensional parameters that control the dynamics of the flow are the Coriolis parameter, $f$, the velocity, $U$, the reduced gravity, $g^{\prime}$, the kinematic viscosity, $v$, and the dense current vertical and horizontal length scales, $H$ and $L$, respectively. The time scale for salt diffusion is approximately $7 \mathrm{~h}$, much longer than the experiment duration, hence salt diffusivity can be neglected. The input flow rate $Q$ is not indicative of the evolution of the flow down-slope, and a local value of the velocity, $U$, is more relevant to the dynamics of the flow. Hence, in addition to the slope, $s$, we expect four independent non-dimensional parameters to play a dynamical role. These are the Froude number, $F r=U / \sqrt{g^{\prime} H \cos \theta}$, the Reynolds number, $R e=U H / v$, the Ekman number, $E k=2 v /\left(f \cos \theta H^{2}\right)$, and the aspect ratio $H / L$. The Rossby number can be obtained by combining three of these, i.e. $\operatorname{Ro}=0.5 \operatorname{Re} \operatorname{Ek}(H / L)$. The dependence of mixing in the dense current on the slope angle, Reynolds and Froude numbers, will be discussed in $\$ 5$ and $\$ 6$. A brief discussion on the effect of the Ekman and Rossby numbers is given in $\S 9$.

\section{Mixing dependence on the slope angle}

The first set of experiments was performed to investigate the mixing dependence on the slope angle. The slope, $s$, was varied between 0.45 and 8.6, while the flow rate, the Coriolis parameter, and the initial reduced gravity were kept constant and set to the values of $Q=2.5 \mathrm{~cm}^{3} \mathrm{~s}^{-1}, f=1 \mathrm{~s}^{-1}$ and $g_{0}^{\prime}=4 \mathrm{~cm} \mathrm{~s}^{-2}$, respectively. The amount of mixing in the dense current was quantified by the mixing ratio measured at the end of the slope, $r_{b}=g_{b}^{\prime} / g_{0}^{\prime}$. A value of $r_{b}=1$ indicates no mixing, while $r_{b} \longrightarrow 0$ when the dense and ambient fluids are completely mixed. Figure 4 shows the dependence of $r_{b}$ on the slope angle (triangles), together with the results of CWAO (circles) with the same values of $Q, f$, and $g_{0}^{\prime}$. The experiments of CWAO were performed for values of $s$ between 0.1 and 0.7 , whereas here we concentrated on the influence of higher slope values. The excellent agreement between the measurements here and those of CWAO of the mixing ratio for $0.45 \leqslant s \leqslant 0.7$ (figure 4) gives us confidence that the experiments are repeatable, and that the measurements are robust and independent of the apparatus details. In addition, such agreement allowed us to complete the investigation of mixing dependence on slope angle started in CWAO for small slope values.

Mixing between the dense and ambient fluids was observed to increase (i.e. decreasing $r_{b}$ ) with the slope angle (figure 4), and the larger increase was found in the range $0.5<s \leqslant 1$, as was partially evident in CWAO. For $s>1$, the mixing increased less rapidly, and for very high values of the slope, $s \geqslant 4$, the mixing ratio reaches a small, but finite value, suggesting that the density current is not completely mixed with the ambient fluid at the end of the slope.

The mixing dependence on the slope angle is related to the form of the flow. For small values of the slope, $s \leqslant 0.3$, the flow behaved as a laminar density current and very little mixing was observed (i.e. $r_{b}=0.98$ ). For higher values of the slope, $0.3<s \leqslant 0.5$, the current had a laminar region close to the source, followed by a wave region (figure $2 a$ ), hence, some mixing was observed (i.e. $0.98<r_{b}<0.88$ ). For 


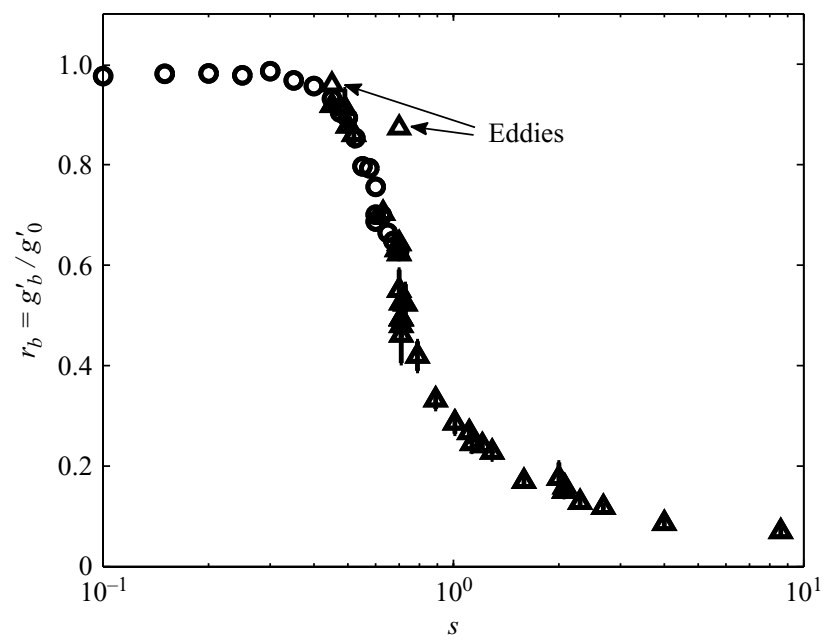

FiguRE 4. Dependence of the mixing ratio measured at the end of the slope, $r_{b}=g_{b}^{\prime} / g_{0}^{\prime}$, on the slope $s$ for $Q=2.5 \mathrm{~cm}^{3}, \mathrm{~s}^{-1}, f=1 \mathrm{~s}^{-1}$, and $g_{0}^{\prime}=4 \mathrm{~cm} \mathrm{~s}^{-2}$. Circles represents the results from CWAO and triangles are the present results. The two triangles indicated as "eddies" had $Q=8.3 \mathrm{~cm}^{3} \mathrm{~s}^{-1}, f=1.75 \mathrm{~s}^{-1}$ and $g_{0}^{\prime}=4 \mathrm{~cm} \mathrm{~s}^{-2}$. Vertical bars indicate the $90 \%$ confidence intervals.

$0.5<s \leqslant 1$, a small increase in the slope produced a large increase in mixing owing to the waves growing in amplitude and breaking in a three-dimensional fashion (figure $2 b$ ). For very steep slopes $s \simeq 1$, a turbulent density current developed (figure 3 ) in which the dense fluid was highly mixed with the ambient fluid. Further increasing the slope $(s>1)$, induced only a relatively small increase in mixing.

In order to investigate systematically the dependence of the mixing on the slope, Reynolds and Froude numbers, we conducted an analysis similar to that in CWAO. As discussed in $\S 1$, the entrainment parameter $E$ is defined as the ratio of the local entrainment velocity, $W e(l)$, to the local velocity of the current, $U(l)$. Both of these velocities vary with distance, $l$, from the source, but previous experimental studies suggest that, to a very good approximation, the ratio of these velocities, the entrainment parameter, is independent of position. In the present study, we were not able to obtain local measurements of $W e(l)$ and $U(l)$. However, we can write

$$
\frac{1}{A} \int_{A} W e(l) \mathrm{d} A=\frac{1}{A} \int_{A} E U(l) \mathrm{d} A,
$$

where $A$ is the area on the slope covered by the density current after a time interval $\Delta t$ (\$2.1). Given the above statement, we assume $E$ is constant in space and define $W e_{m}=(1 / A) \int_{A} W e(l) \mathrm{d} A$ and $U_{m}=1 / A \int_{A} U(l) \mathrm{d} A$, to obtain $E=W e_{m} / U_{m}$, where $U_{m}$ is the average velocity defined in $\$ 2.1$, and $W e_{m}$ is a measure of the average entrainment velocity (i.e. the average vertical velocity at the dense current interface sufficient to obtain the observed mixing between the dense fluid and the fresh overlying fluid over an area $A$ ). Therefore, $W e_{m}$ can be obtained as the ratio of the entrainment flow rate defined by (2.3) and the area $A$

$$
W e_{m}=\frac{Q_{e}}{A}=\frac{1}{A} Q\left(\frac{1}{r_{b}}-1\right) .
$$




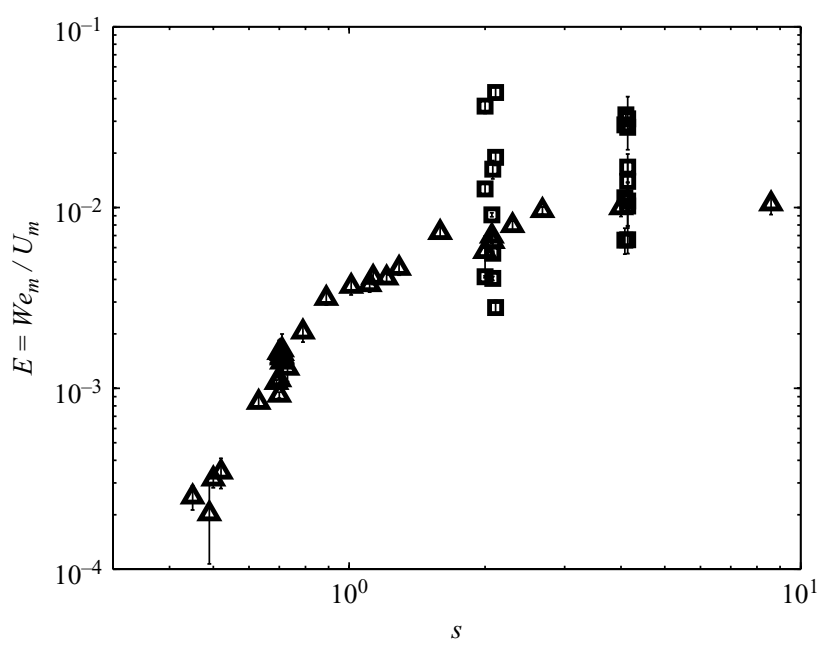

FIGURE 5. Entrainment parameter, $E$, dependence on the slope angle, $s$. Triangles represent the experiments shown in figure 4 in which only the slope angle was varied. Squares represent all the other experiments in which the flow rate, the Coriolis parameter, and the initial reduced gravity were also varied. Error bars are shown for each data point.

For each experiment, we measured the area $A$ on the slope covered by the dense current and used the measured velocity, $U_{m}$, to calculate the entrainment parameter, $E=W e_{m} / U_{m}$. Furthermore, we calculated the bulk height, $H_{m}$, and reduced gravity, $g_{m}^{\prime}$, to estimate the value of the Froude and Reynolds numbers.

Our derivation of the entrainment parameter $E$, using (5.2), is not based on 'local' measurements as in Ellison \& Turner (1959) but instead on 'integral' measurements as in CWAO, Wells \& Wettlaufer (2005) and Wells (2007). E was calculated using average values for both the entrainment and down-slope velocities, representative of an entire experiment. This average definition of $E$ is strictly valid only in currents where the flow regime does not change with distance down the slope. As discussed in $\S 3$, in some experiments two or three regimes occurred successively down the slope. In these cases, usually occurring at low $R e$ for non-turbulent regimes, the average value of $E$ will depend on the slope length, and in particular on the area covered on the slope by each regime. However, in most of the experiments, one regime dominated and covered an area much bigger than the areas covered by the other regimes. Hence, we expect the general trend of $E$ not to change substantially, as shown in $\S 7$, and we will retain this average definition of $E$ even for those experiments in which the flow regime was observed to change with distance down the slope.

For the experiments shown in figure 4, in which only the slope was varied while the flow rate, the Coriolis parameter, and the initial reduced gravity were kept constant, the entrainment parameter increased with increasing slope angles (triangles in figure 5). However, for the experiments in which the slope was kept fixed (i.e. $s \simeq 2$ and $s \simeq 4$ ) while the other parameters were varied, the entrainment parameter varied approximately an order of magnitude (squares in figure 5), indicating that the slope alone is not the relevant parameter regulating the amount of mixing in the dense current. As discussed in the next section, the lack of collapse of the entrainment parameter with the slope angle can be explained by the observed dependence of $E$ on both the Froude and Reynolds numbers. 


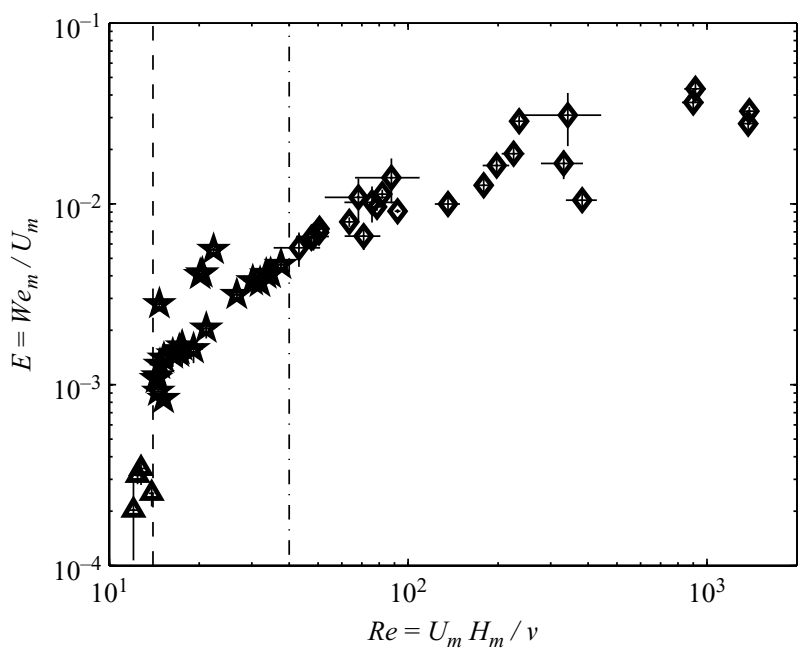

FiguRE 6. Entrainment parameter, $E$, dependence on the Reynolds number, $R e$. Triangles represent the non-breaking-waves regime (figure 2a), stars the breaking-waves regime (figure $2 \mathrm{~b}$ ), and diamonds the turbulent regime (figure 3). The dashed line indicates $R e=14$, and the dash-dotted line indicates $R e=40$. Error bars are shown for each data point.

In order to investigate the mixing between the dense and ambient fluids in the eddy regime (\$3), two experiments at $s=0.45$ and 0.7 were performed with $g_{0}^{\prime}=4 \mathrm{~cm} \mathrm{~s}^{-2}$, $Q=8.3 \mathrm{~cm} \mathrm{~s}^{-1}$, and $f=1.75 \mathrm{~s}^{-1}$ (figure 4). At $s=0.7$, the mixing caused by the eddies (i.e. $r_{b}=0.87$ ) is significantly reduced when compared to the mixing observed for the breaking waves (i.e. $r_{b}=0.63$ ). Most of the dense fluid is now contained in coherent eddies moving approximately across-slope and preventing the wave and turbulent regimes from occurring, hence the eddies stabilize the current and reduce the mixing.

\section{Mixing dependence on Reynolds and Froude numbers}

The entrainment parameter $E$ has a strong dependence on $R e$, as shown in figure 6. In particular, this figure shows the dependence of mixing on $R e$ for the different regimes discussed in $\S 3$. The non-breaking-waves regime (figure $2 a$ ) was observed for $R e<14$ (triangles), the breaking-waves regime (figure $2 b$ ) for $14 \leqslant R e<40$ (stars), and the turbulent regime (figure 3) for $40 \leqslant R e<1386$ (diamonds). For values of $R e<14$, the entrainment parameter was small and approximately constant in the range $2 \times 10^{-4}<E<4 \times 10^{-4}$. For $\operatorname{Re} \sim 14$, a small increase in the Reynolds number produced a large increase in the entrainment parameter from $O\left(10^{-4}\right)$ to $O\left(10^{-3}\right)$. For $14 \leqslant R e<40, E$ increased linearly with increasing $R e$, reaching values just below $E \sim 5 \times 10^{-3}$ for $R e \sim 40$. For $R e \geqslant 40$, the entrainment parameter was observed first to increase linearly at the same rate as for $14 \leqslant R e<40$ and, after approximately $R e \sim 100$, the value of $E$ increased less rapidly, reaching $E \sim 3 \times 10^{-2}$ for $R e \sim 1000$.

For some experiments, the value of the entrainment parameter is larger than the value associated with experiments having the same $R e$ (i.e. the four stars on the left-hand portion of figure 6). This discrepancy is a result of a dependence on the Froude number that is shown in figure 7 for the three different regimes discussed above. The non-breaking-waves regime occurred for $0.9<F r<1.3$ (triangles), 


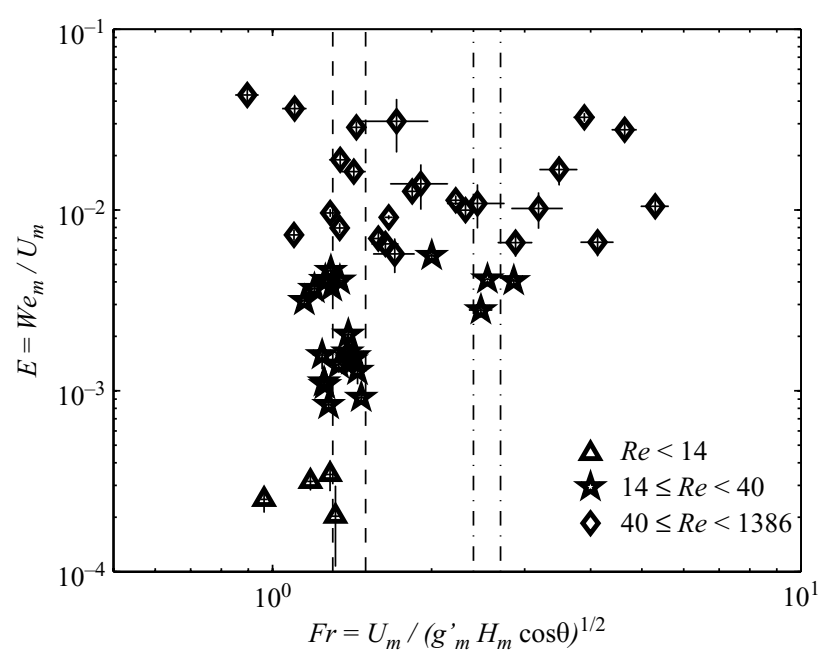

FIGURE 7. Entrainment parameter, $E$, dependence on the Froude number, $F r$, for different ranges of Reynolds number $R e$ characterizing the three regimes discussed in the text. The dashed lines indicate $1.3 \leqslant F r<1.5$, while the dash-dotted lines indicate $2.4 \leqslant F r<2.7$. Error bars are shown for each data point.

whereas for the breaking-waves regime $1.1<F r<2.9$ (stars), and for the turbulent regime $0.9<F r<5.3$ (diamonds). In general, mixing $\left(W e_{m} / U_{m}\right)$ was observed to increase with increasing Froude number. However, we observed that different regimes occurred for approximately the same value of the Froude number and had an entrainment parameter that varied up to two and half orders of magnitude, as observed for the experiments with $1.3 \leqslant F r<1.5$, lying within the two dashed lines in figure 7. This variation is caused by variation in $R e$ for the experiments having approximately the same $F r$, as shown in figure 8 for the experiments limited by the dashed $(1.3 \leqslant F r<1.5)$ and the dash-dotted lines $(2.4 \leqslant F r<2.7)$ in figure 7 . Hence, the entrainment parameter depends not only on $F r$, as assumed by the Ellison Turner (1959) parameterization, (1.1), but also on $R e$, as also seen in figure 6. For a fixed value of $F r$, the entrainment parameter (i.e. mixing) increased owing to an increase in $R e$, as a result of the change in the flow regime from a non-breaking-waves to a breaking-waves to a turbulent regime. Hence, the large values of the entrainment parameter $\left(E \sim 3 \times 10^{-2}\right)$ associated with experiments with low $F r(F r \sim 1)$ can be explained by the large values of $R e$ in these experiments. Furthermore, the discrepancy discussed above between the values of the entrainment parameter for experiments having the same $R e$ in figure 6 (i.e. the four stars on the left) is a result of the larger value of $F r$ in the experiments with larger $E$ compared to those having the same $R e$ and lower values of $E$.

The dependence of $E$ on both $R e$ and $F r$ can be clearly seen in figure 9 in which $E$ is plotted versus $R e F r$, and where some of the scatter of the data present in figures 6 and 7 has disappeared. In particular, the four stars on the left-hand portion of figure 6 showing a discrepancy due to the Froude-number dependence of $E$, collapse with the rest of the data in figure 9. Also, the large scatter in figure 7 observed especially for small $F r$, is reduced when considering a dependence on both $R e$ and $F r$. Some scatter is still present in figure 9 for the turbulent experiments with the largest values of $E$. 


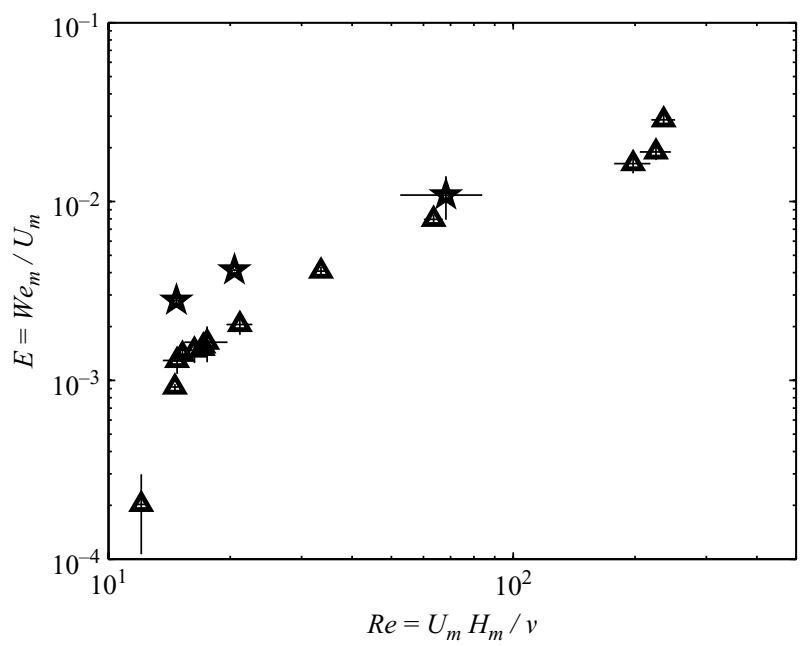

FIGURE 8. Entrainment parameter, $E$, dependence on the Reynolds number, $R e$, for experiments lying in two different ranges of the Froude number: $1.3 \leqslant F r<1.5$ (triangles), and $2.4 \leqslant F r<2.7$ (stars). Error bars are shown for each data point.

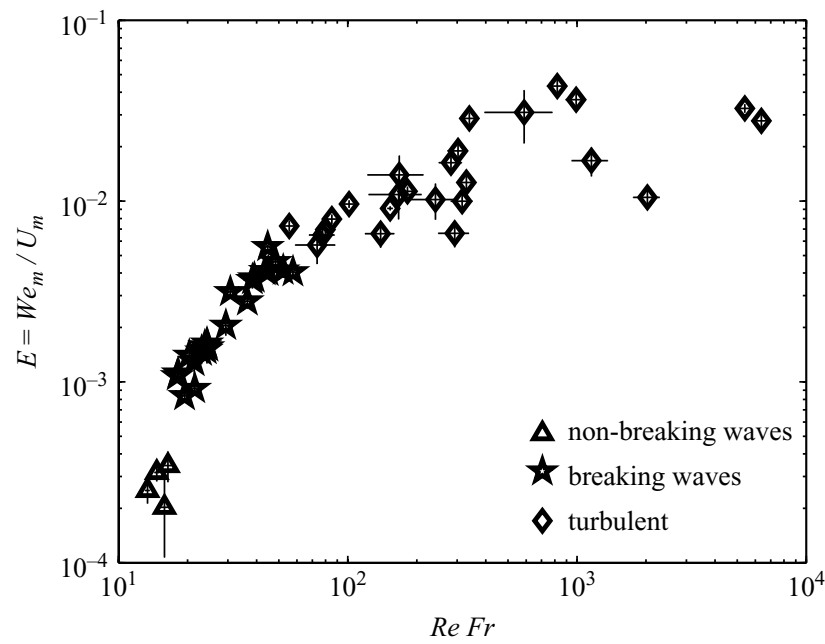

FIGURE 9. Entrainment parameter, $E$, dependence on both the Froude and Reynolds numbers, $\mathrm{ReFr}$, for the three regimes discussed in the text. Error bars are shown for each data point.

\section{Evaluation of mixing at four locations on the slope}

A set of experiments was performed to investigate how mixing within a dense current evolves while the current flows down the slope. Density measurements taken at four locations on the slope (figure $1 b$ ) were used to compute the value of the reduced gravity, $g^{\prime}(l)$, from (2.1). Figure 10 shows the mixing ration $r(l)$ for three representative experiments with high (triangles, $R e=900$ ), intermediate (circles, $R e=43.1$ ), and low (squares, $R e=14.6$ ) Reynolds numbers.

For high Reynolds numbers (triangles, $R e=900$ ) a turbulent density current was observed to develop immediately after the source (figure $3 b$ ) as confirmed by the measured high mixing at the beginning of the slope $\left(A^{\prime}, l=12 \mathrm{~cm}\right)$. Here in after, by 


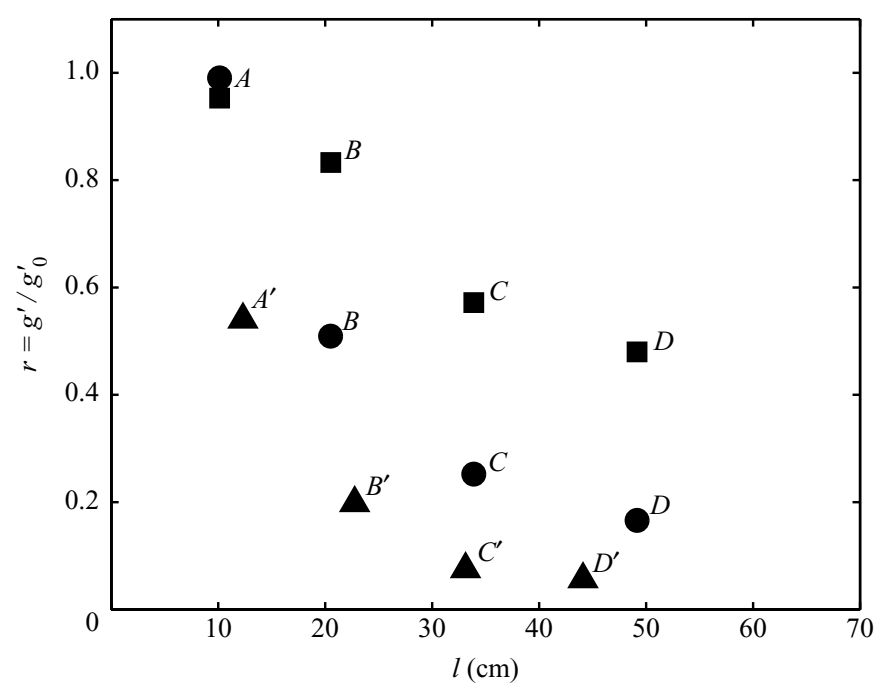

FIGURE 10. Mixing dependence on down-slope distance. Solid triangles: high Reynolds number, $R e=900\left(F r=1, Q=8.3 \mathrm{~cm}^{3} \mathrm{~s}^{-1}, f=1 \mathrm{~s}^{-1}, g_{0}^{\prime}=99.8 \mathrm{~cm} \mathrm{~s}^{-2}, s=2\right)$. Solid circles: intermediate Reynolds number, $R e=43.1\left(F r=1.7, Q=2.5 \mathrm{~cm}^{3} \mathrm{~s}^{-1}, f=1\right.$ $\left.\mathrm{s}^{-1}, g_{0}^{\prime}=4 \mathrm{~cm} \mathrm{~s}^{-2}, s=2\right)$. Solid squares: low Reynolds number, $\operatorname{Re}=14.6(F r=1.5, Q=2.5$ $\mathrm{cm}^{3} \mathrm{~s}^{-1}, f=1 \mathrm{~s}^{-1}, g_{0}^{\prime}=4 \mathrm{~cm} \mathrm{~s}^{-2}, s=0.7$.

'high mixing' we mean at least a $50 \%$ reduction in $r(l)$ that, by definition, is equal to 1 at the source, and $r_{b}$ at the end of the slope. In these experiments, the density current keeps mixing, and reducing its density until the location on the slope marked by $C^{\prime}$, where the density current is almost completely mixed (i.e. $r(l)=0.075$ ) with the ambient fluid.

Similar results were obtained for experiments with a lower Reynolds number (circles, $R e=43.1$ ) at which value the current remained turbulent. A laminar region close to the source was observed (figure $3 a$ ), giving no appreciable change in the mixing ratio at the first measurement location $(A, l=10 \mathrm{~cm})$. Most of the mixing occurred when the density current was in the turbulent region (locations $B, C$ and $D$ ).

For experiments with low Reynolds numbers (squares, $R e=14.6$ ) different regimes were observed as the flow descended down-slope: laminar, non-breaking waves and breaking-waves, as shown in figure $2 b$. No appreciable mixing occurred at the first measurement location $(A)$, i.e. in the laminar region; most of the mixing occurred downstream of the start of the breaking-waves region, located between $B$ and $C$. For low $R e$ experiments, the start of the breaking-waves region was observed to move toward the source as the $R e$ of the experiment increased, causing a reduction of the non-breaking-waves region and a consequent increase of the measured mixing at a fixed location. As shown in figure 10, mixing for low Re (i.e. waves regime, figure 2) was considerably lower than for large $R e$ (i.e. turbulent regime, figure 3 ) at all four locations on the slope.

In those experiments in which density measurements were taken at four locations on the slope, the values of the bulk parameters described in $\$ 2.1$ were calculated also with the averaging done over the area on the slope covered by the dense current between two consecutive measurement locations, i.e. between the source and location $A$, between locations $A$ and $B$, and so on. From these bulk parameters, the values of $E, F r$ and $R e$ were calculated for each experiment at four locations on the slope. 


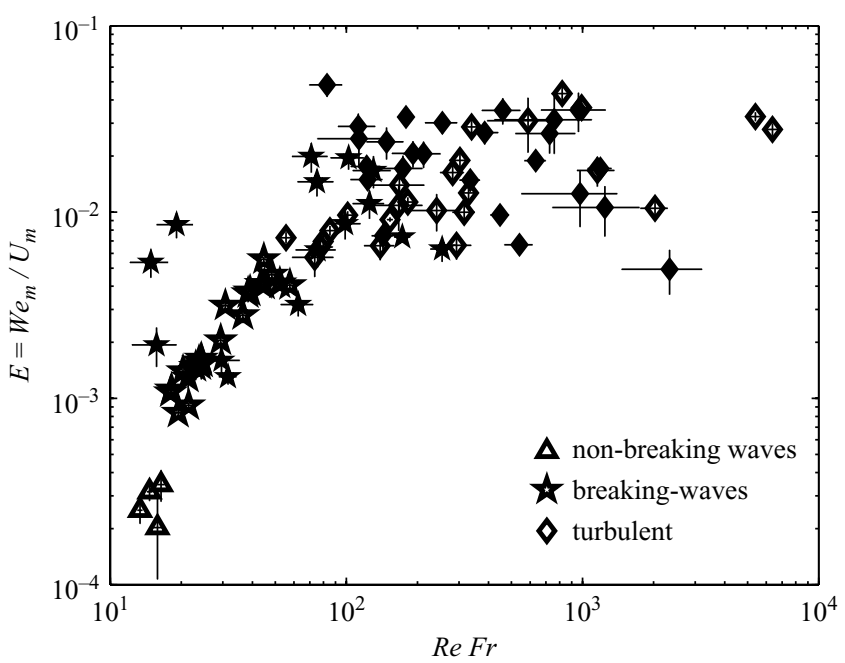

FiguRE 11. Entrainment parameter, $E$, dependence on both the Froude and Reynolds numbers, ReFr, for the three regimes discussed in the text. Open symbols show the same data as figure 9. Solid symbols show the data collected at three locations on the slope for a selected number of experiments. Error bars are shown for each data point.

Figure 11 shows the same data as figure 9 (open symbols) with added data collected at three locations on the slope (solid symbols) for a selected number of experiments (the data between the source and location $A$ are not shown, given the large uncertainty in the measurements). These data (solid symbols) present a larger scatter when compared to the data in figure 9 (open symbols). Such scatter is partly due to a larger error in the measurements taken at the four locations on the slope, as indicated by the larger error bars for the solid symbols in figure 11. As discussed in $\S 5$, the bulk value of $E$ measured for each experiment (open symbols) is appropriate only when the flow regime of the dense current does not change as the flow descends the slope. However, the general trend of $E$ does not change substantially when a more 'local' estimate of $E$ was calculated at different locations on the slope, as shown by the solid symbols in figure 11. This result gives us confidence that the general dependence of $E$ on the $F r$ and $R e$ discussed in $\S 6$ is robust and not influenced by the slope length.

\section{Comparison with observations and previous laboratory studies}

The increase in entrainment parameter with increasing Froude number shown in figure 7 is a robust result previously found in laboratory experiments of both rotating (CWAO; Wells 2007) and non-rotating dense currents (Ellison \& Turner 1959; Wells $\&$ Wettlaufer 2005), and in theoretical (Turner 1986) as well as observational studies (Price \& Barringer 1994; Dallimore, Imberger \& Ishikawa 2001; Girton \& Sanford 2003; Mauritzen et al. 2005; Princevac, Fernando \& Whiteman 2005; Arneborg et al. 2007) (figure 12).

As discussed in $\S 6$, in this study the entrainment parameter showed a dependence on both $R e$ and $F r$ numbers. For $F r \simeq 1$ and low $R e$, the entrainment parameter measured in the present laboratory experiments had comparable order of magnitude to, or slightly underestimated, mixing observed in the ocean. As expected, for 


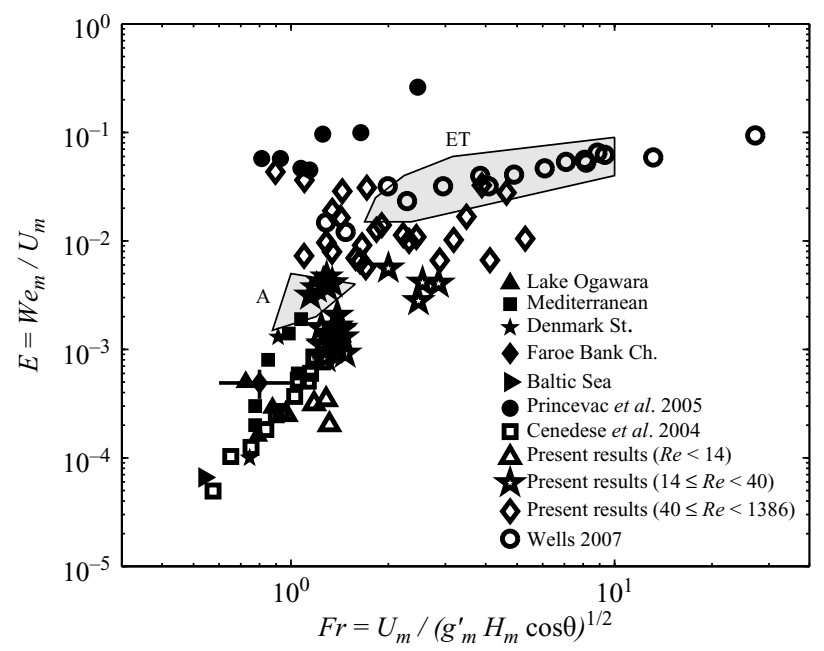

FIGURE 12. Dependence of the entrainment parameter $E=W e_{m} / U_{m}$ on the Froude number. Solid and open symbols are used for observational and laboratory data, respectively. Shaded areas represent the non-rotating laboratory experiments of Ellison \& Turner (1959) (ET) and Alavian (1986) (A).

intermediate Reynolds numbers $(14 \leqslant R e<40)$ (the breaking-waves regime), $E$ was an order of magnitude lower than that obtained in the high-Reynolds-number and turbulent non-rotating experiments of Ellison \& Turner (1959) and Wells \& Wettlaufer (2005) and the rotating experiments of Wells (2007). However, for higher $\operatorname{Re}(\operatorname{Re} \sim 1000)$ (a fully turbulent density current), the present experiments had values of $E$ comparable to previous turbulent laboratory experiments. It is worth noting that most of the present experiments within the turbulent regime, presented values of $R e<400$ (figure 6), whereas the previous experiments mentioned above reached values of $R e$ up to $10^{3}$. A dependence of $E$ on $R e$ has been observed up to values of $R e=10^{7}$. Hence, a larger value of $E$ is expected for the previous studies when compared to most of the present experiments within the turbulent regime (with $R e<400$ ). The slight differences between the present laboratory values of entrainment and the previous ones could be also due to the different methods used to measure $E$ and the fact that, in the present experiments, extreme care was taken to avoid mixing at the source, possibly resulting in lower values of $E$ than in Ellison \& Turner (1959), Wells \& Wettlaufer (2005) and Wells (2007). Furthermore, the present laboratory experiments spanned a wider range of $F r$ and $R e$ when compared to previous laboratory experiments. Hence, here we were able to identify the dependence of the entrainment parameter on both $R e$ and $F r$.

A comparison of $E$ measured in atmospheric katabatic flows (Princevac et al. 2005) having $R e \sim 10^{7}$ with that measured by Ellison \& Turner (1959) in experiments having $R e \sim 10^{3}$ shows a similar strong dependence of $E$ on $R e$ for a fixed value of $F r$. The katabatic flows had values of the entrainment parameter significantly larger than those of Ellison \& Turner (1959), about a factor of five at $F r=1.4$ and an order of magnitude larger at $F r=2.2$ (solid circles in figure 12). Furthermore, entrainment was also observed to occur for subcritical Froude numbers, as is the case for oceanic observations (solid symbols in figure 12).

Finally, it is worth noting that similar observations were made in stratified turbulence experiments (Ivey \& Imberger 1991; Strang \& Fernando 2001) in which 
the mixing efficiency was found to be dependent on both $F r$ and $R e$ and non-zero values of mixing efficiency were found for $F r<1$.

\section{Discussion and conclusions}

The amount of mixing occurring within a density-driven current flowing down a sloping bottom in a rotating fluid has been investigated in the laboratory. We expect five non-dimensional parameters to play a dynamical role (\$4). The present experiments focused on the influence on mixing of the slope, Reynolds and Froude numbers. The Ekman and Rossby numbers were not varied systematically, i.e. we kept constant $v$ and $f$. Hence, the mixing dependence on these two parameters can be explained in light of the three non-dimensional parameters discussed $(s, \operatorname{Re}$ and $\mathrm{Fr}$ ). The mixing increased with decreasing Ekman number in the range $0.2<E k<1.2$ for $R e<40$ and gave a sharp increase in the range $0.007<E k \leqslant 0.2$ for $R e \geqslant 40$. The above results reflect the high mixing observed for high $R e$, whereas the small values of $E k$ for large mixing are mainly due to the increase of the current height, $H_{m}$, associated with the large mixing and entrainment. The determination of the Rossby number is delicate since it involves a choice for the horizontal length scale $L$. If the horizontal length scale dominating geostrophic rotating flows, i.e. the Rossby radius of deformation, was chosen, i.e. $L=\sqrt{g_{m}^{\prime} H_{m}} /(f \cos \theta)$, then $R o \equiv F r$. A more appropriate length scale is the distance travelled by the dense current down-slope, i.e. $L=l$. Near the source, we do not expect rotation to be important, however for $R o \leqslant 0.2$ (Fleury et al. 1991), we expect rotation to influence the entrainment and the dynamics of the flow. The distance down-slope $l=l_{\text {rot }}$, at which $R o=0.2$, increases with increasing $E$. For the non-breaking-waves and breaking-waves regimes $l_{\text {rot }} \leqslant 10$ $\mathrm{cm}$, indicating that in these regimes, rotation is important for most of the flow descent (the slope length is $60 \mathrm{~cm}$ ). For the turbulent regime and $R e \leqslant 100$, rotation is important on the lowest $2 / 3$ of the slope, i.e. $10<l_{\text {rot }} \leqslant 20 \mathrm{~cm}$. As the entrainment and the Reynolds number increase, $l_{\text {rot }}$ increases and for three experiments it is larger than the slope length, indicating that rotation does not influence those flows. This result is expected since an increase in $R o$ is due either to an increase of the velocity scale (i.e. $F r$ or $R e$ ) or to $s$, both of which have been observed to increase mixing. Furthermore, those currents influenced by rotation deflect to the right (looking downstream) and widen owing to viscous forces draining fluid down-slope in a thin layer. On the other hand, when a current flows down-slope with little deflection (indicating a small influence of rotation), it does not widen as much. Hence, we believe that the fluid entrained produces mainly an increase in the current height and not width, since the width of the current is inversely proportional to the entrainment parameter.

The mixing within the density current, evaluated at the end of the slope, increased with increasing slope angle when keeping the flow rate, the Coriolis parameter and the initial reduced gravity fixed. In particular, for $0.5 \leqslant s<1$, a small increase in the slope angle produced a relatively large increase in mixing. For very large slopes, $s \geqslant 4$, a very small, but finite, value of the mixing ratio $r_{b}=g_{b}^{\prime} / g_{0}^{\prime}$ was measured (i.e. $r_{b}=0.007$ ), indicating that the density current did not completely mix with the ambient fluid. Results for $s \leqslant 0.7$ are in good agreement with CWAO data. However, experiments in which the other parameters were varied indicated that the slope alone is not the relevant parameter regulating the amount of mixing in the dense current.

The amount of mixing that a density current undergoes while descending down a slope is highly dependent on both the flow Froude and Reynolds numbers. To our 
knowledge, this is the first set of rotating experiments, spanning Froude numbers in the range $0.8<F r<10$ and Reynolds numbers in the range $10<R e<1400$, in which mixing has been quantified within the different regimes observed: laminar, waves (non-breaking and breaking), turbulent and eddies. Mixing was observed to increase suddenly with increasing $R e$ for $R e \sim 14$, while for $R e \geqslant 14$, the entrainment parameter first increased linearly and then, after approximately $R e \sim 100$, less rapidly to reach a value of $E \sim 3 \times 10^{-2}$ for $R e \sim 1000$. Mixing $\left(W e_{m} / U_{m}\right)$ was also observed to increase with increasing Froude number. However, the strong dependence of mixing on $R e$ caused a large variation of the entrainment parameter value for experiments having similar values of $F r$. For large $F r$ and $\operatorname{Re}(\operatorname{Re} \sim 1000), E$ had similar values to those obtained in the high-Reynolds-number and turbulent non-rotating experiments of Ellison \& Turner (1959) and Wells \& Wettlaufer (2005), and the rotating experiments of Wells (2007). Furthermore, for low $F r$ and low $R e$, it had a comparable order of magnitude to mixing observed in the ocean. As already pointed out by Wåhlin \& Cenedese (2006) and Hughes \& Griffiths (2006), the subcritical mixing observed in CWAO and in some of the present experiments, could be of fundamental importance when determining the final water mass characteristics (for example density) of a dense current descending the continental slope following a long path. Therefore, a weak, but non-zero, entrainment can substantially change the final density and, consequently, the location of important water masses, such as NADW, in the open ocean water column. Hence, a future development of our ongoing work is to suggest a new entrainment parameterization that allows for subcritical Froude number entrainment and takes into account the effect of both the $F r$ and $R e$ on entrainment. This new parameterization will, consequently, differ substantially from the Ellison \& Turner (1959) parameterization still widely used. The Wåhlin \& Cenedese (2006) comparison of the Ellison \& Turner (1959) and CWAO low-Froudenumber parameterization suggests that major differences in the basin stratification could occur, in the case of small slopes, depending on the parameterization used.

We wish to thank Mary-Louise Timmermans, Mathew Wells and Jack Whitehead for invaluable discussions, carefully reading drafts and substantially improving the clarity of the manuscript. Support was given by the National Science Foundation project number OCE-0350891. The laboratory experiments were carried out with the able assistance of Keith Bradley. We also thank one anonymous reviewer for useful comments on an earlier version of this manuscript.

\section{REFERENCES}

Aagaard, K., Coachman, L. K. \& Carmack, E. C. 1981 On the halocline of the Arctic Ocean. Deep-Sea Res. 28, 529-545.

Alavian, V. 1986 Behavior of density currents on an incline. J. Hydraul. Engg. ASCE 112, 27-42.

Arneborg, L., Fiekas, V., Umlauf, L. \& Burchard, H. 2007 Gravity current dynamics and entrainment - A process study based on observations in the Arkona Basin. J. Phys. Oceanogr. 37, 2094-2113.

Baines, P. G. 2001 Mixing in flows down gentle slopes into stratified environments. J. Fluid Mech. 443, 237-270.

BaInes, P. G. 2002 Two-dimensional plumes in stratified environments. J. Fluid Mech. 471, 315-337.

BAINES, P. G. 2005 Mixing regimes for the flow of dense fluid down slopes into stratified environments. J. Fluid Mech. 538, 245-267.

Baringer, M. O. \& Price, J. F. 1997 Mixing and spreading of the Mediterranean outflow. J. Phys. Oceanogr. 27, 1654-1677. 
BRitter, R. E. \& Linden, P. F. 1980 The motion of the front of a gravity current travelling down an incline. J. Fluid Mech. 99, 531-543.

Cenedese, C., Whitehead, J. A., Ascarelli, T. A. \& Ohiwa, M. 2004 A dense current flowing down a sloping bottom in a rotating fluid. J. Phys. Oceanogr. 34, 188-203.

DALlimore, C. J., Imberger, J. \& IshiKaWA, T. 2001 Entrainment and turbulence in saline underflow in Lake Ogawara. J. Hydraul. Eng. 127, 937-948.

Dickson, R. R. \& Brown, J. 1994 The production of North Atlantic deep water: sources, rates and pathways. J. Geophys. Res. 99, 12 319-12 341.

Ellison, T. H. \& Turner, J. S. 1959 Turbulent entrainment in stratified flows. J. Fluid Mech. 6, 423-448.

Etling, D., Gelhardt, F. Schrader, U. Brennecke, F. Kuhn, G. Chabert D’Hieres, G. \& Didelle, H. 2000 Experiments with density currents on a sloping bottom on a rotating fluid. Dyn. Atmos. Oceans 31, 139-164.

EzER, T. 2005 Entrainment, diapycnal mixing and transport in threedimensional bottom gravity current simulations using the Mellor-Yamada turbulence scheme. Ocean Modell. 9, 151-168.

EzER, T. 2006 Topographic influence on overflow dynamics: idealized numerical simulations and the Faroe Bank Channel overflow. J. Geophys. Res. 111 (C02002) doi:10.1029/2005JC003195.

Fleury, M., Morr, M., Hopfinger, E. J. \& Auchere, D. 1991 Effects of rotation on turbulent mixing across a density interface. J. Fluid Mech. 223, 165-191.

Foster, T. D. \& CARMack, E. C. 1976 Frontal zone mixing and Antarctic Bottom Water formation in the southern Weddell Sea. Deep-Sea Res. 23, 301-317.

Girton, J. B. \& Sanford, T. B. 2003 Descent and modification of the overflow plume in Denmark Strait. J. Phys. Oceanogr. 33, 1351-1364.

Hughes, G. O. \& Griffiths, R. W. 2006 A simple convective model of the global overturning circulation, including effects of entrainment into sinking regions. Ocean Modell. 12, 46-79.

Ivey, G. N. \& Imberger, J. 1991 On the nature of turbulence in a stratified fluid. Part I: The energy of mixing. J. Phys. Oceanogr. 21, 650-658.

Jackson, L., Hallberg, R. W. \& LegG, S. 2008 A parameterisation of shear-driven turbulence for ocean climate models. J. Phys. Oceanogr. (in press).

JIANG, L. \& GARWOOD, W. J. 1996 Three-dimensional simulations of overflows on continental slopes. J. Phys. Oceanogr. 26, 1224-1233.

Jungclaus, J. H., Hauser, J. \& Käse, R. H. 2001 Cyclogenesis in the Denmark Strait overflow plume. J. Phys. Oceanogr. 31, 3214-3229.

Käse, R. H., Girton, J. B. \& SAnford, T. B. 2003 Structure and variability of the Denmark Strait Overflow: model and observations. J. Geophys. Res. 108(C6), 3181, doi:10.1029/2002JC001548.

Killworth, P. D. 1977 Mixing on the Weddell Sea continental slope. Deep-Sea Res. 24, 427-448.

LANe-Serff, G. F. \& Baines, P. G. 1998 Eddy formation by dense flows on slopes in a rotating fluid. J. Fluid Mech. 363, 229-252.

LegG, S., Hallberg, R. W. \& GirTon, J. B. 2006 Comparison of entrainment in overflows simulated by $z$-coordinate, isopycnal and nonhydrostatic models. Ocean modell. 11, 69-97.

Mauritzen, C., Price, J., Sanford, T. \& Torres, D. 2005 Circulation and mixing in the Faroese Channels. Deep-Sea Res. II 52, 883-913.

ÖzGÖKmen, T. M., Fischer, P. F. \& Johns, W. E. 2006 Product water mass formation by turbulent density currents from a high-order nonhydrostatic spectral element model. Ocean Modell. 12, 237-267.

Price, J. F. \& Barringer, M. O. 1994 Outflows and deep water production by marginal seas. Prog. Oceanogr. 33, 161-200.

Price, J. F., Baringer, M. O., Lueck, R. G., Johnson, G. C., Amabar, I., Parrilla, G., Cantos, A., Kennelly, M. A. \& SAnford, T. B. 1993 Mediterranean outflow mixing and dynamics. Science 259, 1277-1282.

Princevac, M., Fernando, H. J. S. \& Whiteman, D. C. 2005 Turbulent entrainment into natural gravity driven flows. J. Fluid Mech. 533, 259-268.

Riemenschneider, U. \& LegG, S. 2007 Regional simulations of the Faroe Bank Channel overflow in a level model. Ocean Modell. 17, 93-122.

Saunders, P. M. 1990 Cold outflow from the Faroe Bank Channel. J. Phys. Oceanogr. 20, 29-43.

Simpson, J. E. 1997 The Anatomy of a Gravity Current. Gravity Currents in the Environment and the Laboratory, 2nd edn, Cambridge University Press pp. 140-163. 
Smith, P. C. 1975 A streamtube model for bottom boundary currents in the ocean. Deep-Sea Res. 22, 853-873.

Spall, M. A. \& Price, J. F. 1998 Mesoscale variability in Denmark Strait: the PV outflow hypothesis. J. Phys. Oceanogr. 28, 1598-1623.

Strang, E. J. \& Fernando, H. J. S. 2001 Entrainment and mixing in stratified fluis. J. Fluid Mech. 428, 349-386.

Sutherland, B. R., Nault, J., Yewchuk, K. \& Swaters, G. E. 2004 Rotating dense current on a slope. Part-1. Stability. J. Fluid Mech. 508, 241-264.

TURNER, J. S. 1986 Turbulent entrainment: the development of the entrainment assumption and its application to geophysical flows. J. Fluid Mech. 170, 431-471.

WÅhlin, A. K. \& Cenedese, C. 2006 How entraining density currents influence the ocean stratification. Deep-Sea Res. II 53, 172-193.

Wells, M. G. 2007 Influence of Coriolis forces on turbidity currents and their sediment patterns. In Proc. Euromech Colloquium-477.

Wells, M. G. \& Wettlaufer, J. S. 2005 Two-dimensional density currents in a confined basin. Geophys. Astrophys. Fluid Dyn. 99, 199-218.

Whitehead, J. A., Stern, M. Flierl, G. \& Klinger, B. 1990 Experimental observations of baroclinic eddies on a sloping bottom. J. Geophys. Res. 95, 9585-9610.

Xu, X., Chang, Y. S., Peters, H., Özgökmen, T. M. \& Chassignet, E. P. 2006 Parameterization of gravity current entrainment for ocean circulation models using a high-order 3D nonhydrostatic spectral element model. Ocean Modell. 14, 19-44. 